DOI: $10.2478 /$ rjp-2020-0010

\title{
THE COUPLE OBJECT
}

R. Roussillon ${ }^{14}$

Abstract: The author argues for a conception of the oedipal complex that excludes the idea of a pre-oedipal phase which, according to him, comes from a confusion with the pre-genital. The author seeks to identify the existence of a "couple object" present early on in the young child whose pre-history he returns to in the first lineaments of a form of "being with", as in the first form of recording relational models concerning the meeting with the first objects. This matrix will then be made more complex over time and brought into crisis in the "oedipal crisis", and the way in which the child will be able to meet and go through this crisis, to organize himself and to organize the solutions to the crisis, will configure its model of "oedipal organization".

Keywords: Oedipus, patterns of being with, couple object, precocious interactions, oedipal crisis, oedipal organization.

\section{Introduction}

To introduce the reflections which I am proposing on what is called the Oedipus complex, to me it seems necessary to start by evoking terminological questions insofar as these exploit the exchange on this question and are at the origin of a significant number of misunderstandings. 
When, in the 1960s, certain theoreticians of French psychoanalysis proposed to individualize "narcissism" and "narcissistic instances" in order to oppose them to the drive life, the custom was formed, in the psychoanalytic vulgate or current exchange, to superimpose the pregenital with what was then called the "pre-oedipal", thus confusing the question of drive organization with the relational matrix in which it is deployed. This conceptual inflection, of which there is only a small trace left in Freud himself, is at the origin of a whole series of theoretical inflections (and we could see the "good oedipal mothers" bloom, as opposed to the pregenital "phallic" stepmothers), which I am not sure have helped to clarify either the clinic or the theoretical debates. In the psychoanalytic world and, more generally, in the world of clinicians who recognize themselves as part of the "psychoanalytic field", nobody is able to legislate on the proper use of concepts and one can only be content to advance reflection through collective debate.

Personally, I find that my position, both theoretical and clinical, has been clarified by a series of distinctions that are all prerequisites for what I wish to develop in my present reflection.

As far as I'm concerned, I carefully differentiate what we call "pregenital" and that which concerns infantile libidinal organizations (even if Freud recognizes the existence of an infantile "genital" organization, I prefer to continue, again for the sake of conceptual clarity, to speak of "phallic organization"), some "pre-oedipal" phase which for me is meaningless. This position leads me to differentiate various axes of the oedipal issue.

Each child, whether he likes it or not, whether he is aware of it or not, has been constructed based not only on the fact that he is the fruit of the sexual encounter of two adults, but also on the fact that he owes an important part of his psychic organization to the relational models in which he was plunged as a child, and to the types of identifications that he was able to resort to in order to deal with the question of this influence (Freud, 1921). We build ourselves, with our father and mother ${ }^{15}$, in the encounter with the peculiarities of one and the other, in the encounter with the organization of the relational model of their couple. The human subject is not intelligible to me without the reference to the history of its construction in connection with

\footnotetext{
${ }^{15}$ Of course, in my formula one must read "father and mother" as a short way to mean any significant adult person from childhood, significant meaning here instinctively invested, i.e. in a position to occupy the place of the father or mother.

138
} 
this identity matrix. This is the whole question of the oedipal problem. This is also the matrix of meaning, because, in this perspective, what happens with an object is never fully intelligible without reference to what happens with another object, an "object of the object" because the object is also an "othersubject", it is also subject to desires that are specific to it.

This principle is known as that of thirdness. It means that there is no human relationship without a third party, whether it is recognized and represented or not, whether it is included or excluded, whether it is masked, repressed, denied... It is a basic principle, a foundation of clinical listening of relations and bonds, but of course it does not state that it is indifferent on whether the third party is recognized or represented or not, whether it is repressed, excluded or included, whether it is hidden or manifest... Moreover, the whole clinical question will be closely determined by what can be recognized and accepted from the link between the object and a third party, the "object of the object", by what will be repressed, denied or split from this link. From this point of view, the Oedipus complex is a "gift" of human intelligibility, a present that exists from birth, even if at that time it cannot yet be conscious and fully appropriated.

It is indeed another question than that of knowing how this "present" will become appropriable and how the human subject will be able to organize its presence and its effect. If the oedipal "present" is indeed there right from the start, it will only be appropriable from the moment when this state of affairs can be brought into the present of relations, when it will be able to be dramatized within intra-family exchanges. This moment is when something already present will be able to be brought into crisis and come to the fore. It is the moment of the "oedipal crisis", or what is called in short, sometimes too quickly, the Oedipus complex.

We will return later to the question and the conditions for this "crisis setting" of the oedipal problem.

This crisis, which is an "identity" crisis, a crisis focusing on the conditions for the establishment of human identity, being a son or daughter of a father and mother, the difference in gender and difference in intertwined generations, will have to be organized, or rather the subject will have to organize himself in this crisis just as much as he will have to organize the crisis itself and the paradoxes it implies. We do not "leave" the oedipal complex, it 
does not "dissolve", we organize ourselves in it - we organize the crisis and the outcomes, the possible modes of satisfaction.

\section{Forms and conditions of the oedipal crisis}

So here we are with three "forms" of the Oedipus complex, that of its effect of structure or preconception, of potentiality, if we want to use more modern language, that of its crisis setting and that of its organization.

Neurosis thus appears not as the oedipal structure but as one of its models of organization. Conversely, psychosis rather confronts a subjectivity which, if it has possibly started to confront the oedipal crisis, has ebbed below it, failing to organize the crisis and to organize itself in the crisis, failing to organize and recognize the third-party function. Therefore, it also tends to organize "against" what it could not organize or signify. It becomes antioedipus, but the anti-oedipal is "oedipal", it is a form of the oedipal complex ${ }^{16}$, a "distorted" form of it. In patients diagnosed as being borderline, I have often noticed that the third was hidden behind incorporative processes that made it unrecognizable for a long time.

It is not my goal to do the psychopathology concerning forms of the oedipal complex so I am only indicating in passing how one can think of the complexity its forms.

Therefore, two main questions arise. The first concerns the conditions that make the oedipal crisis "approachable", i.e. which make its crisis possible. The second concerns the relevance and generativity of the modes of organization of the crisis.

These questions are immense and it would take an entire book to pretend to begin to understand the complexity that they profile. I would be content with a few remarks to advance them, a few remarks that certain advances in contemporary clinical practice allow to be more easily formulated.

\section{Patterns of being and doing with}

My first remark is based on an observation by our colleagues in neuroscience and by developmental psychologists: the child, and already the

\footnotetext{
${ }^{16}$ In the work L'enfant de Ça [The Infant of the Id] (1973), A. Green and J-L. Donnet emphasize that the oedipal complex can be deformed so as not to succumb. For them too there is no non-oedipal. They describe a form, the split oedipal complex that testifies to this extreme deformation "so as not to succumb". 
baby, does not confuse his two parents. There is not a primary object from which a father / mother difference is secondarily generated. Babies "categorize" the experiences they can have with either parent in different regions of their own, without confusion and from very early on. The child's mother "category" is getting richer and more complex, as is his father "category".

In the same way, modern attachment theorists (I am thinking in particular of those from the LTP school in Lausanne - E. Fivaz-Depeursinge, A. Corboz-Warnery) show that babies are very capable, again very early on, to develop a mode of relation not only to one parent or the other, but to the interaction of the parents with one another, a relation to the parental "couple". There is therefore a "primary triangle" and the possibility for the baby to be sensitive to his parents' way of interacting, and this very early on. It is not a question of what could have been called an "early oedipus" complex, a concept which is based on the confusions that I emphasized above, but of the demonstration of the possibility for the baby to be in contact with the model of relationship that his two parents have with each other.

If we have to look for the matrix originating from the concept of "couple" in early childhood, we must also evoke, alongside the primary triangle, the question of what D. Stern calls "patterns of relating with others". Stern's hypothesis is that babies build, using their experience of meeting with their mother, father or anyone significant in their environment, a "model" of the meeting with them and its characteristics. These "patterns of being with others" are forms of what Bowlby called "internal working models". It can no longer be argued (Dornes, 2002) that babies would have a very early fantasy life, at least without modifying the meaning of the concept of fantasy deeply enough and identifying it completely with the concept of representation or that of process. This does not mean that there are no early representations, as the functioning of the brain is a fundamentally "representative" functioning (Varela, 1989) based on the organization of an associative decomposition / recomposition of experience, but that these are not organized as "fantasies" or "phantasms". More likely they would be "representactions" according to the terminology of J.D. Vincent, i.e. representations or patterns of actions, representations of a way of relating to the other, of reciprocal action of one on the other, elementary patterns of treatment of the experience, "to do together" patterns (drive). We can evoke the pictograms of P. Aulagnier, the formal signifiers of D. Anzieu or the signifiers of demarcations described by G. Rosolato... as many forms as I proposed to subsume under the concept of "primary symbolization". 
My hypothesis is that these "patterns of being with others" and of "doing together" are the first matrices of what it is to "be and form a couple", that they can be invested as a psychic "object", as an "object" for the organization of the drive. So, I think that these patterns are the preform of what will become "the couple object", at the center of the oedipal configuration and its organizer.

Therefore, it seems to me that it is on the side of their configuration that we must seek the conditions of possibility of the oedipal crisis and, in particular, of their "opening", of their objectifying generativity. Let me explain.

\section{Presentation of the father}

There is a "critical moment" in the relationship between the baby and his mother, a critical moment during which, whatever the quality of the relationship between father and baby, the mother electively becomes the one who can reassure the baby. This can be quite dramatic when, for example, the father is the main agent of motherhood, as in some Swedish families who for various reasons, including economic reasons - the mother earns more than the father so they "chose" the father as the one to take maternity leave.

Towards the 7th-8th month, and in a significant way, the mother becomes the main comforter, whereas, a few weeks or even days before, the father could very well perform this function with equal relevance. The mother becomes "the regulating object of the self" (D. Stern), the one that devolves the function of being the baby's emotional mirror. For his part, C. Bollas proposed designating this particular function of the primary object as "transformational object". It has been noted that it was during this "critical period" that something began to be organized concerning the "presentation" of the father by the mother, i.e. the emergence of the father's role as the mother's sexual object. Against the background of this regulatory function that makes the mother an object like no other, which makes the mother "the object" par excellence, the primary vector of instinctual life, the "presentation" of the father (as a "sexual partner" ${ }^{17}$ ) by the mother changes the meaning that it takes within the relationship. It is this transition that would fail in the process of "foreclosure of the Name-of-the-Father" described by Lacan, a failure in the process by which the father is "designated" by the mother as her privileged, referent object.

\footnotetext{
${ }^{17}$ This means that the mother "assigns" the father as the "cause" for a certain kind of emotions that are specifically addressed to him, emotions that contain the preconception of a father as a referential sexual "partner" of the mother.
}

142 
We could also speak of "precocious Oedipus" complex when referring to this type of phenomenon, when, conversely, it goes well enough.

This official "presentation" itself provides the preform and one of the preconditions so that, when the question of the representation of the absent object will be at the center of the "agenda" of psychic maturation, the absence of the mother can be represented as a "presence elsewhere", typically with the father.

Let us stop here for a moment on a psychic aspect that is not sufficiently emphasized in my opinion.

The possibility of representing the fact that the absent object is present elsewhere relies on the organization and maintenance of the representation of the fact that, when the object is absent, the child nevertheless continues to be present in the maternal psyche. The acquisition of the permanence of the object, i.e. the permanence of the object's investment - the cognitive permanence of the object is acquired much earlier (Rochat, 2006) - supposes the "mirrored" representation of that of the permanence of the baby for the mother. It is on the basis of this observation that the mother, in absence, "has not forgotten" the child, that the permanent investment of the object is set up as a "mirror" through the representation of that object.

J-L. Donnet in an article titled "we are talking about a child" was able to emphasize, in many cultural figures as well as in many clinical treatment episodes, the frequency of the representation of the fact that, when the parents are "among themselves", they talk about the child. It suffices only to remember the beginning of the tale "Hop-o'-My-Thumb" to measure the generativity of this formation. This is also why, something which Freud has always emphasized, in the fantasy of the primitive scene "the child attends the scene of his own conception", he is there present in thought, the thoughts of the mother, of the father, at the very moment when he is conceived. In thought, ensuring a form of continuity, reciprocity, not "perceptually" preserves it and maintains a gap, a difference or even a protective exclusion.

Thus, the child gradually slides from the organization of his patterns of "being with the object" to patterns of "being of the object with another object" and something of his primary relationship to it transfers on the relation from the object to the object of the object. He goes from models and patterns of his relationship to the maternal object to patterns and models of his mother's relationship to his father. 


\section{The ability to be alone in the presence of the couple}

There is then another subjective experience that is completely essential for the psychic organization of its relation to the "couple object", an intermediate experience between the "being with", the "doing together with" and the "being excluded" from the couple, between the experience of being at the center of the parental couple and that of being excluded from it. Winnicott was able to point out that the space between absence and presence was interspersed with the experience of "being alone in the presence of the object". I proposed to refine its formulation by adding "facing one's drive alone". In continuation of Winnicott's intuition, I proposed to describe secondary forms of the experience of "being alone in the presence of the object", and, in particular, that of "being alone in the presence of the couple" (Roussillon, 1995, 1999, 2008).

In this case the parental couple is present and the two parents are in relation with each other. The child is also present, on a separate stage, "on the side", he plays. He plays a game that we could call "couple": he plays at being a "couple", the first form of the Mom-And-Dad games.

The drive commitment within the parental couple remains moderate, but the two parents are present to each other. The presence of the child is put on hold, ready to resurface if the discussion between the parents becomes agitated, forgotten if it becomes passionate.

The child also remains discreet. He leaves the parental couple alone in his presence, he explores within his game, in echo, what is played on the stage between the parents, appropriating it. But if the relationship between the two parents threatens to heat up too much, he also remains ready to remind them of his presence and try to interrupt what is beginning. The advantage of the subjective experience of being "alone in the presence of the couple" is that it allows the child to simultaneously explore the double experience of being alone (and therefore of being able to play the "couple object") and to be in the presence of the couple to measure the potential impact of his game on it. $\mathrm{He}$ is both excluded from the couple and present in it - he is "facing" the couple.

I was able to advance the hypothesis that this intermediate subjective experience also "prepared the organization of the primitive scene, of a primitive scene in which the child would be both included and excluded, both present in 
the representation and absent in fact, i.e. the complementary scene. To fully understand this "anticipatory and preparatory function", it is necessary pay attention to the fact that, if the overflowing parts of the drives intervening within the parental couple are disorganizing for the quality of "the experience of being alone in the presence of the couple", conversely the absence of any drive commitment between them makes the subjective experience lose all value. Again, it should be said "alone in the face of the drive in the presence of the couple". This implies that one of the child's "motives" for the game of playing at being a couple must be sought in what is nevertheless engaged with the drives, even if this engagement remains moderate, in the situation. My hypothesis is that the stake is then that of the introjection and the integration "fragment by fragment" of the drive motions within the conceptual matrix of the couple object, of this organizer of the oedipal configuration. It is through this work that the drives are inscribed in the question of creativity and even creation. It is there that they gradually fall into order according to it.

\section{The Oedipal game}

My closing remarks, in this necessarily limited overview, will focus on the drama of the crisis of the Oedipus complex.

To begin, a first remark: the "oedipal triangle" cannot be thought of without integrating the topic of siblings.

This question is too often forgotten in reflections on the Oedipus complex. It is likely that the traumatic aspects of Freud's relationship with his siblings (death of his brother Julius) and the relative ${ }^{18}$ silence to which they led him, for a long time hindered sufficient consideration of the matrix nature of the topic of siblings within the oedipal configuration ${ }^{19}$. However, a number of works in recent years ${ }^{20}$ have begun to emphasize the importance of the fraternal "complex" and of various aspects relating siblings and the fraternal topic in psychic organization and narcissistic regulation.

\footnotetext{
${ }^{18}$ Relatively because there are in fact quite a few traces of this topic in his work, the subject of the horde of brothers is the most fundamental example.

${ }^{19} \mathrm{We}$ can also recall, concerning this matter, that the question of brotherhood, of the wold pack, is one of the key arguments of the work of Deleuze and Guattari, which, in its time (1971) hit the headlines: L'anti-œdipe [Anti-Oedipus: Capitalism and Schizophrenia, published in 1972 in English].

${ }^{20} \mathrm{We}$ will simply evoke, as an example of studies on the fraternal topic, the one by O. Bourguignon and the even more recent one by R. Jaitin.
} 
However, to my knowledge, the essential character of this (almost structural) question in the oedipal configuration has not been underlined.

For me, the openness on the issue of siblings, whether it is only potential or whether it is actually embodied in the child's life, is an inherent part of the analysis of the oedipal configuration. A couple that is thought of only by a single child would remain a narcissistic couple, conceived from the point of view of the child, from the point of view of the narcissism of the child. The generativity of the couple object implies more than one child. It implies the potential of more than one child. It cannot be exhausted in the only child. The rivalry is necessarily both intra-generational and intergenerational, and one cannot go without the other or be treated without the other.

My second comment will focus on the deployment and progressive complexification of the "being with" and "doing together" patterns produced following the integration of complex forms of differentiation. The first forms of these patterns are in fact set in order by the question of the union and the differentiation of the ego and the non ego, and even if they are immediately marked by the difference of sexes and generations, these are not seen as organizing. The gradual introduction of the gender difference and its irreversible nature will precipitate the first forms of the oedipal crisis. The system of "anal consolation" based on the potential reversal ("when I will be big and you will be small") and the deferred ("it will grow later", what falls [from the body] will return [to it] later) is gradually being put into default by discovering the existence of two sexes, and by the progressive discovery of the irreversible nature of this difference. The difference between the self and another subject, always tempered before by the action of a background of "double" relationships (Roussillon, 2004), encounters a point of radicalization that contributes to precipitating the crisis while also undermining the previous narcissistic defenses. At the same time this radicalization will allow the nonspecular aspects of the self / other difference to find a field of experience to be put to work, dramatized and therefore developed.

However, irreversibility also carries a consequence on the organization of temporality. The "anal stage" is a cyclical time, a time of the "deferred return of the same", as what is lost or released will be found identical later. The irreversible nature of the difference between the sexes is thus linked to the irreversible character of the difference in generation and the chronological temporality thus involved. 
Consequently, the "logic" of everything, which presides over the organization of infantile narcissism, will collide with the factual observations that we have just noted. If, on one hand, the "couple object" is set up as the very figure in which the narcissistic ideal had believed it could take refuge, on the other hand it comes up against the complex forms of differentiation which block its refuge.

From then on, the drama of family interactions will bear witness to the struggle within, or against this central problem.

According to a first direction, the logic of the whole tries to maintain itself by attempting to exclude exclusion. All situations, such as the child's bedtime, in which the question arises, will be plagued by strategies to try to prevent it. The child wants mom and dad together at his bedside. As soon as the parents start talking to each other or trying to be alone together, he manifests himself, multiplies provocations which aim to put an end to these attempts...

When all goes well enough the parents tolerate a certain success of these maneuvers, and also put limits to their invasion of family life. Another "game" can then unfold, if one cannot exclude the exclusion when it concerns one or another member of the family, be it father, mother, or another child.

The child of the oedipal crisis will therefore play one parent against the other and try to attack the couple who exclude him. It will make the two adult giants "fight", as in the story of the little tailor, by activating situations in which a potential conflict between them can arise.

Or he will play on the exclusion of one of the two parents by trying to form a couple "with the other". At bedtime, he will carefully choose whether his father or mother will help him with brushing his teeth, putting on pajamas, the final moment of bedtime etc.

\section{Conclusions}

We have brought together the classical figures of the Oedipus complex and it is time to stop there and to say, in the end, that there is no "resolution" of the Oedipus complex, but there is a progressive organization of the conflictuality that inhabits it, an organization that will fundamentally integrate the oedipal complex of the child's own parents and their reactions 
to the different strategies that the child may have implemented. It is this organization and that of the superego which embodies the quintessence that will produce the appeasement of the crisis.

The configuration of the Superego will establish then what are the models of actualization or realization of the desires that can be implemented and what are those which fall under the prohibited category. It will establish what can be achieved in action, what must be satisfied to be realized only in the act of language and of what must be limited to thoughts in the intimacy of the inner world.

\section{REFERENCES}

ANZIEU, D. (1987). Les signifiants formels et le moi-peau [Formal signifiers and the I-skin].

In Les enveloppes psychiques [Psychic envelopes]. Dunod, Paris, pp. 1-22.

AULAGNIER, P. (1975). La Violence de l'interprétation [The Violence of interpretation]. PUF, Paris.

BOLLAS, C.H. (1989). L'objet transformationnel [The transformational object], Rev Fr Pschanal, N4, 1181-1199. PUF, Paris.

BOWLBY, J. (1969). Attachement et Perte [Attachment and Loss], vol. 1, L'Attachement [Attachment]. PUF, Paris, 1978.

BOWLBY, J. (1973). Attachement et Perte [Attachment and Loss], vol. 2, La Séparation: angoisse et colère [Separation: anxiety and anger]. PUF, Paris, 1978.

BOWLBY, J. (1980). Attachement et Perte [Attachment and Loss], vol. 3, La Perte: tristesse et dépression [Loss: Sadness and Depression]. PUF, Paris, 1984.

BOURGUIGNON, O. et coll. (1999). Le Fraternel [The Fraternal]. Ed Dunod, Paris.

DELEUZE, G., GUATTARI, F. (1971). L'anti-cedipe [The antiOedipus]. Ed. de minuit, Paris.

DONNET, J-L. (1995). On parle d'un enfant [We're speaking of a child], in Le divan bien tempéré [The well-tempered sofa]. PUF, Paris. 
DORNES, M. (2002). Psychanalyse et psychologie du premier âge [Psychoanalysis and psychology of the first age], French translation by C. Vincent. PUF, Paris.

GREEN, A., DONNET, J-L. (1973). L'enfant de Ça [The Infant of the Id]. Ed. de Minuit, Paris.

FIVAZ-DEPEURSINGE, E., CORBOZ-WARNERY, A. (1999). The Primary Triangle. A Development System View of Mothers, Fathers and Infants. Basic Books, New York. (French translation by O. Jacob, Le triangle primaire. Ed. Odile Jacob, Paris, 2001.)

RAITIN, R. (2006). Clinique de l'inceste fraternel [The Brotherly Incest Clinic]. Dunod, Paris.

ROCHAT, P. (2006). Le monde des bébés [The world of babies]. Ed. Odile Jacob, Paris.

ROSOLATO, G. (1987). Le sacrifice [The sacrifice]. PUF, Paris.

ROUSSILLON, R. (1995). La métapsychologie des processus et la transitionnalité [The metapsychology of processes and transitionality], Rev Franç Psychanal, Numéro Spécial Congrès.

ROUSSILLON, R. (1999). Agonie, clivage et symbolisation [Agony, splitting and symbolisation]. PUF, Paris.

ROUSSILLON, R. (2003). La séparation et la chorégraphie de la présence [Separation and the choreography of the presence]. In La séparation [Separation]. Erés, Toulouse.

ROUSSILLON, R. (2004). La dépendance primitive et l'homosexualité primaire « en double » [Primary addiction and primary homosexuality "in double"], Rev Franç Psychanal, LXVIII, 2:421-439. PUF, Paris.

STERN, D. (1985). Le Monde interpersonnel du nourrisson [The Interpersonal World of the Infant]. French translation, PUF, Paris, 1989.

VARELA, F. (1989). Connaître les Sciences cognitives [Knowing Cognitive Sciences]. Seuil, Paris.

VINCENT, J-D. (1986). Biologie des passions [The Biology of Passions]. Ed. Odile Jacob, Paris. 
VINCENT, J-D. (2004). La compassion. Le cour des autres [Compassion. The heart of others]. Ed. Odile Jacob, Paris.

WINNICOTT, D.W. (1969). De la pédiatrie à la Psychanalyse [From Paediatrics to Psychoanalysis]. Payot, Paris.

WINNICOTT, D.W. (1970). Le processus de maturation chez l'enfant [The Maturational Processes of the Child]. Payot, Paris.

WINNICOTT, D.W. (1971). Jeu et réalité [Playing and Reality]. Gallimard, Paris.

WINNICOTT, D.W. (1989). La crainte de l'effondrement et autres situations cliniques [Fear of breakdown: a clinical example]. Gallimard, Paris, 2000. 